\title{
Prevalence of Vaccine Hesitancy towards Childhood Vaccination Program among Guardians Attending Primary Health Care in Bahrain
}

\author{
Zainab S. Adel ${ }^{1 *}$, Alya Hasan ${ }^{1}$, Eman Ahmed ${ }^{1}$, Hamad Alterafi ${ }^{1}$, Salwa AlSammak ${ }^{1}$, Jaleela Sayed Jawad ${ }^{2}$, Fatima
} Hubail $^{3}$

${ }^{1}$ FPRP resident, Ministry of Health, Kingdom of Bahrain

${ }^{2}$ MBBS, ABFM, MSC, DLSTHM, Consultant Family Physician, Kingdom of Bahrain

${ }^{3}$ Consultant Family physician, Kingdom of Bahrain

DOI: $10.36348 /$ SJNHC.2019.v02i09.001 $\quad$ | Received: 29.08.2019| Accepted: 05.09.2019| Published: 12.09 .2019

*Corresponding author: Zainab S. Adel

\section{Abstract}

Vaccine hesitancy is considered to be a threat to the success of vaccination program and control of infectious diseases. It affects the morbidity and mortality thus overwhelms the health care system. Up to our knowledge there is no formal study done to assess vaccine hesitancy in Bahrain. The aim and objectives of this study is to determine the prevalence of vaccine hesitancy towards childhood vaccination in Kingdom of Bahrain. A cross sectional study was conducted in Bahrain's five health regions. One primary health care center was selected randomly from each health region. Participants were systematically selected; every third attendant was asked to fill a self-administer PACV questionnaire. A total of 707 participants were enrolled in the study. This study found that $5.8 \%$ of participants were hesitant to vaccinate their children. Non-Bahraini were found to be more hesitant than Bahraini. In addition, 33.3\% of the hesitant participants delayed their child's vaccination and $38.2 \%$ decided not to have their child vaccinated for reasons other than illness or allergy. Most of the hesitant participants had concerns about vaccine safety, as $65.9 \%$ of the hesitant participants were concerned that the child might have a serious side effect from the vaccine, $63.4 \%$ were concerned that childhood vaccines might not be safe and more than two third of them preferred that their children get fewer vaccines at the same time. However, $45.9 \%$ of the hesitant participants have trust issues about their child's doctor. Although Kingdom of Bahrain has a high immunization coverage and low prevalence of hesitancy towards childhood's vaccines, addressing vaccine hesitancy is important to maintain the high vaccination coverage and prevent communicable diseases targeted by vaccination.

Keywords: Vaccine hesitancy, childhood immunization, primary health care.

Copyright @ 2019: This is an open-access article distributed under the terms of the Creative Commons Attribution license which permits unrestricted use, distribution, and reproduction in any medium for non-commercial use (NonCommercial, or CC-BY-NC) provided the original author and source are credited.

\section{INTRODUCTION}

Vaccination plays a significant role in controlling communicable diseases and it is one of the most successful and cost-effective interventions to improve health outcome. Vaccine hesitancy is a global concern. It affects the mortality and morbidity as well as increasing infection outbreaks. Vaccine hesitancy defined as: "delay in acceptance or refusal of vaccines despite availability of vaccination services. Vaccine hesitancy is complex and context specific, varying across time, place and vaccines. It is influenced by factors such as complacency, convenience and confidence". Vaccine hesitancy is affected by these three factors: first one is the confidence, which means the trust people have in the efficacy and safety of the vaccination as well as in the vaccine's providers. The second is complacency which is the perception of risks related to vaccine-preventable diseases is low thus the vaccine is no longer necessary as preventive action. The last factor that affects vaccine hesitancey is convenience which consists of the availability of vaccines, are people willing to take the vaccine?, Is it affordable?, Can they reach it? And how much they know about the vaccination program [1].

Many studies were conducted in different countries regarding vaccine hesitancy. In the United States, a collective report review was done to assess the state of vaccine confidence for parents of children below 6 years. It was found that $79 \%$ of parents were confident or very confident regarding vaccination. While overall studies in USA concluded that 1 out of 5 
parents were not confident about vaccine safety and its importance. Additionally, some data showed that the percentage of parents who delayed at least one vaccination increased from $21.8 \%$ in 2003 to $25.8 \%$ in 2009 [2]. Furthermore, a study was conducted in Canada to assess the knowledge, attitudes and beliefs of parents about vaccination against seasonal influenza and pneumococcal infections. This study found that $80.4 \%$ of children were vaccinated up to date, $40.2 \%$ of parents were hesitant to have their children vaccinated with some vaccines and $58.2 \%$ of the hesitant parents have vaccinated their children. Moreover, the three main reasons contributed to hesitancy in this study were: fear of adverse events, low severity of the vaccine preventable disease and doubts about vaccines with a percentage of $36 \%, 30 \%, 14.3 \%$ respectively [3].

In Europe, a qualitative study was conducted in several countries to assess the determinants of vaccine hesitancy among healthcare providers. Research teams from Croatia, France, Greece and Romania have participated in this study. The results showed that concerns related to vaccines were country and context specific. Healthcare workers had concerns related to risks of vaccination and expressed a lack of trust in health authorities. Some healthcare workers were also against vaccination in general, Greek healthcare workers thought that the numbers of vaccines children received were very high and the vaccines prevented illnesses are not serious, while in Croatia there was a strong fear of serious adverse events. In addition, the doctors of all the countries mentioned showed mistrust in pharmaceutical companies due to their financial interest [4].

A study was done in Taif area in Saudi Arabia to assess Parent's Knowledge and Attitudes on Childhood Immunization found that $73 \%$ strongly agreed or agreed on the safety of vaccines. On the other hand, $40 \%$ of parents were not sure of vaccine safety [5].

Another study done in Tabuk area in Saudi Arabia in 2017 about factors attributed to hesitancy such as the beliefs about the safety and efficacy of vaccines, it was found that $4.8 \%$ of parents believe that their children received too many vaccinations. Additionally, the study found that $60 \%$ of the parents believe that it is better for their children to develop immunity by getting sick rather than being vaccinated [6].

In the Kingdom of Bahrain, the routine childhood vaccination is provided free of charge to Bahraini and residents children through the primary health care facilities located in accessible distance [2].

The routine vaccination coverage in kingdom of Bahrain exceeded $95 \%$ for more than a decade [8].
However, vaccine hesitancy was not assessed previously. Accordingly, this research was conducted to assess the prevalence of hesitancy of guardians attending primary healthcare toward childhood vaccination in kingdom of Bahrain.

\section{METHOD}

Study design: Cross sectional study

Setting: The study was conducted in the primary health care in the period between 2017 to 2018 .

Population and recruitment: Guardians of children attending primary health care.

Sample Size: The sample size was determined by using easy sample size calculator [9. The adult population in Bahrain was 1,127,837 and assuming the prevalence of hesitancy is $50 \%$ as regional study showed vaccine hesitancy prevalence was $40 \%$ [10]. By using 95\% confidence interval, the estimated sample size was 385 . Then, the sample size calculated multiplied by 1.5 to overcome the cluster effect, so the sample size equals 577 [5]. The sample size further increase to 700 in order to increase precision.

Sampling technique: From each of the five health regions, one primary health care centre was selected randomly. Naim, Sitra, Hidd, Kuwait and Yousif Engineer health centres were selected. From each primary health care centre 140 guardians were invited to participate. The selection was done by systematic randomization; every third guardian attended was asked to participate. If a guardian refused to participate, the next in the list was taken. After explaining the research purpose and taking a verbal consent, the PACV (parent attitudes about childhood vaccines) questionnaire paper in English or Arabic form was handed to them. Participants who could not read or write were excluded.

Inclusion Criteria: Guardians attending primary care during the study period

Exclusion Criteria: Guardianswho could not read or speak English or Arabic.

Investigation tool: A validated PACV (parent attitudes about childhood vaccines) questionnaire that was designed by Douglas J [11]. Permission for using the questionnaire was obtained. The questionnaire was translated from English to Arabic then retranslated to English. Pilot study was conducted.

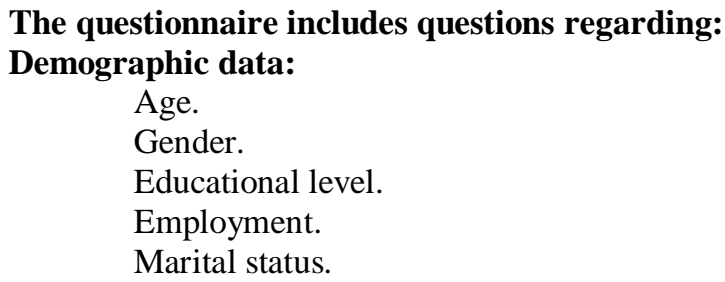


- Six questions about immunization behaviour

- Eight questions about beliefs about vaccine safety and efficacy

- One question regarding attitudes about vaccine mandates and exemptions

- Three questions about trust

\section{Rating: Weight of Questions}

The scoring system was used according to the method approved for PACV study. (Attached in the appendix)

- $\quad$ Score each of the 15 PACV survey items (Q3-Q17; see attached scored version of PACV). Hesitant responses are assigned 2, 'don't know or not sure' 1 , and non-hesitant responses 0 . The two items in which the 'don't know' response was excluded as missing data (Q3 and Q4) are scored 2 for the hesitant response and 0 for the non-hesitant response.

- Calculate the raw total PACV score by simply summing each item. The total raw score will range from $0-30$ if all items have responses and Q3 and Q4 are not excluded as missing data. If there is at least one item without a response or Q3 or Q4 are answered as 'don't know' and therefore are excluded as missing data, the total raw score needs to be adjusted. For instance, if there is one response missing or excluded, the total raw score will range from $0-28$; if there are two responses missing or excluded, the total raw score will range from 0 26; etc. 3. Convert the raw score to $0-100$ scale using simple linear transformation accounting for items with missing values (see attached score conversion chart).

\section{Statistical Analysis}

SPSS statistics version 23.0 was used for data entry and analysis, through which hesitancy rate was calculated as well as frequencies, percentages and confidence interval were computed for categorical variables. The relationship between vaccine hesitancy and demographic data has been tested using chi square test and exact fisher test, with $\mathrm{p}$ - value of 0.05 considered significant.

\section{Ethical Considerations}

The permission to use PACV was taken from the author. The participants were invited to fill the selfadministrative questionnaire. Furthermore, it was explained that the study would be in the benefit of the participants and there would be no harm. Confidentiality of participants was maintained using unique numbers of each questionnaire with no personal identifiers.

\section{RESULTS AND DISCUSSION}

Demographic Data

Response rate $99.5 \%$. The majority of participants were Bahraini representing $82.5 \%$ and about two third of the participants were in the age category between 25-44 years. Approximately, 10\% of participants had educational level below high school (Table-1).

Table-1: Participant's Characteristics of guardian's

\begin{tabular}{|c|c|c|}
\hline & & n (\%) \\
\hline \multirow{4}{*}{$\begin{array}{l}\text { Age } \\
\mathrm{n}=663 *\end{array}$} & $<25$ & $32(4.8 \%)$ \\
\hline & $25-34$ & $322(48.6 \%)$ \\
\hline & $35-44$ & $240(36.2 \%)$ \\
\hline & $45+$ & $69(10.4 \%)$ \\
\hline \multirow{2}{*}{$\begin{array}{l}\text { Nationality } \\
\mathrm{n}=687 *\end{array}$} & Bahraini & $567(82.5 \%)$ \\
\hline & Non- Bahraini & $120(17.5 \%)$ \\
\hline \multirow{2}{*}{$\begin{array}{l}\text { Marital status } \\
\mathrm{n}=702 *\end{array}$} & Married & $682(97.2 \%)$ \\
\hline & Unmarried & $20(2.8 \%)$ \\
\hline \multirow{5}{*}{$\begin{array}{l}\text { Educational level } \\
\mathrm{n}=700 *\end{array}$} & Below high school & $69(9.9 \%)$ \\
\hline & High school & $214(30.6 \%)$ \\
\hline & Diploma & $136(19.4 \%)$ \\
\hline & Bachelor & $217(31.0 \%)$ \\
\hline & Master o more & $64(9.1 \%)$ \\
\hline \multirow{4}{*}{$\begin{array}{l}\text { Monthly income in BD } \\
\mathrm{n}=690 *\end{array}$} & 400 or less & $242(35.1 \%)$ \\
\hline & $>400-800$ & $231(33.5 \%)$ \\
\hline & $>800-1250$ & $132(19.1 \%)$ \\
\hline & $>1250$ & $85(12.3 \%)$ \\
\hline \multirow{4}{*}{$\begin{array}{l}\text { Number of children } \\
\mathrm{n}=696 *\end{array}$} & One & $154(22.1 \%)$ \\
\hline & two & $215(30.9 \%)$ \\
\hline & Three & $156(22.4 \%)$ \\
\hline & Four or more & $171(24.6 \%)$ \\
\hline \multirow{2}{*}{$\begin{array}{l}\text { First child } \\
\mathrm{n}=701 *\end{array}$} & Yes & $210(30.0 \%)$ \\
\hline & No & $491(70.0 \%)$ \\
\hline \multirow{3}{*}{$\begin{array}{l}\text { Relationship to this child } \\
\mathrm{n}=703 *\end{array}$} & Mother & $386(54.9 \%)$ \\
\hline & Father & $279(39.7 \%)$ \\
\hline & Others & $38(5.4 \%)$ \\
\hline
\end{tabular}




\section{Prevalence of Hesitancy}

The prevalence of hesitancy among the study sample was 5.8\% [95\% CI (4.2-7.8)] (Table-2).

Table-2: Prevalence of Vaccine Hesitancy among Guardians Attending Primary Health Center

\begin{tabular}{|l|l|l|}
\hline \multicolumn{2}{|c|}{} & $\mathbf{N}(\boldsymbol{\%}) \mathbf{( 9 5 \%}$ CI) \\
\hline \multirow{3}{*}{ Hesitancy } & Not hesitant & $666(94.2 \%)(92.2-95.8)$ \\
\cline { 2 - 3 } & Hesitant & $41(5.8 \%)(4.2-7.8)$ \\
\cline { 2 - 3 } & Total & $707(100.0 \%)$ \\
\hline
\end{tabular}

The relation between the participant's characteristics and hesitancy Table-3

This study showed no statically significant association between hesitancy and participant's characteristics including age, marital status, educational level and income. However, non-Bahraini nationality were more hesitant than Bahraini, 9.6\% and 4.9\% respectively, with $\mathrm{P}$-value of 0.044 as demonstrated in Table-3.

Table-3: Characteristic of hesitant

\begin{tabular}{|c|c|c|c|c|c|}
\hline & \multicolumn{2}{|l|}{ Hesitancy } & \multirow{3}{*}{$\begin{array}{l}\text { P- } \\
\text { value }\end{array}$} & \multirow{3}{*}{$\begin{array}{l}\text { Test Was } \\
\text { used }\end{array}$} \\
\hline & & Not hesitant & \multirow{2}{*}{$\begin{array}{l}\text { Hesitant } \\
\text { n (\%) }(95 \% \text { CI })\end{array}$} & & \\
\hline & & n (\%) $(95 \% \mathrm{CI})$ & & & \\
\hline \multirow[t]{4}{*}{ Age } & $<25$ & $30(93.8 \%)(79.2-99.2)$ & $2(6.3 \%)(0.76-20.8)$ & \multirow[t]{4}{*}{0.220} & \multirow{4}{*}{$\begin{array}{l}\text { Fisher's Exact } \\
\text { Test }\end{array}$} \\
\hline & $25-34$ & $299(93.0 \%)(89.5-95.4)$ & $23(7.1 \%)(4.6-10.5)$ & & \\
\hline & $35-44$ & $229(95.4 \%)(92.0-97.7)$ & $11(4.6 \%)(2.3-8.1)$ & & \\
\hline & $45+$ & $68(98.6 \%)(92.2-100.0)$ & $1(1.4 \%)(0.04-7.8)$ & & \\
\hline \multirow[t]{2}{*}{ Nationality } & Bahraini & $539(95.1 \%)(92.9-96.7)$ & $28(4.9 \%)(3.3-7.1)$ & \multirow[t]{2}{*}{0.044} & \multirow[t]{2}{*}{ Chi-Squared } \\
\hline & Non-Bahraini & $123(90.4 \%)(84.2-94.8)$ & $13(9.6 \%)(5.2-15.8)$ & & \\
\hline \multirow[t]{2}{*}{ Marital status } & Married & $643(94.3 \%)(92.3-95.9)$ & $39(5.7 \%)(4.1-7.73)$ & \multirow[t]{2}{*}{1.000} & \multirow{2}{*}{$\begin{array}{l}\text { Fisher's Exact } \\
\text { Test }\end{array}$} \\
\hline & Unmarried & $19(95.0 \%)(75.1-100.0)$ & $1(5.0 \%)(0.13-25.0)$ & & \\
\hline \multirow{5}{*}{$\begin{array}{l}\text { Educational } \\
\text { level }\end{array}$} & Below high school & $65(94.2 \%)(85.8-98.4)$ & $4(5.8 \%)(1.6-14.2)$ & \multirow[t]{5}{*}{0.962} & \multirow{5}{*}{$\begin{array}{l}\text { Fisher's Exact } \\
\text { Test }\end{array}$} \\
\hline & High school & $201(93.9 \%)(89.8-96.7)$ & $13(6.1 \%)(3.3-10.2)$ & & \\
\hline & Diploma & $130(95.6 \%)(90.6-98.4)$ & $6(4.4 \%)(1.6-9.4)$ & & \\
\hline & Bachelor & $204(94.0 \%)(90.0-97.0)$ & $13(6.0 \%)(3.2-10.0)$ & & \\
\hline & Master or above & $60(93.8 \%)(84.8-98.3)$ & $4(6.3 \%)(1.7-15.2)$ & & \\
\hline \multirow{4}{*}{$\begin{array}{l}\text { Monthly } \\
\text { income in BD }\end{array}$} & 400 or less & $231(95.5 \%)(92.0-97.7)$ & $11(4.5 \%)(2.3-8.0)$ & \multirow[t]{4}{*}{0.185} & \multirow{4}{*}{$\begin{array}{l}\text { Fisher's Exact } \\
\text { Test }\end{array}$} \\
\hline & $>400-800$ & $211(91.3 \%)(87.0-95.0)$ & $20(8.7 \%)(5.4-13.1)$ & & \\
\hline & $>800-1250$ & $127(96.2 \%)(91.4-99.0)$ & $5(3.8 \%)(1.2-8.6)$ & & \\
\hline & $>1250$ & $81(95.3 \%)(88.4-99.0)$ & $4(4.7 \%)(1.3-11.6)$ & & \\
\hline \multirow{4}{*}{$\begin{array}{l}\text { Number of } \\
\text { children }\end{array}$} & One & $143(92.9 \%)(87.6-96.4)$ & $11(7.1 \%)(3.6-12.4)$ & \multirow[t]{4}{*}{0.637} & \multirow[t]{4}{*}{ Chi-Squared } \\
\hline & Two & $204(94.9 \%)(91.0-97.4)$ & $11(5.1 \%)(2.6-9.0)$ & & \\
\hline & Three & $146(93.6 \%) 88.5-97.0)$ & $10(6.4 \%)(3.1-11.5)$ & & \\
\hline & Four or more & $164(95.9 \%)(91.7-98.3)$ & $7(4.1 \%)(1.7-8.3)$ & & \\
\hline \multirow[t]{2}{*}{ First child } & Yes & $194(92.4 \%)(88.0-96.0)$ & $16(7.6 \%)(4.4-12.1)$ & \multirow[t]{2}{*}{0.219} & \multirow[t]{2}{*}{ Chi-Squared } \\
\hline & No & $466(94.9 \%)(92.6-96.7)$ & $25(5.1 \%)(3.3-7.4)$ & & \\
\hline \multirow{3}{*}{$\begin{array}{l}\text { Relationship to } \\
\text { this child }\end{array}$} & Mother & $361(93.5 \%)(90.6-95.8)$ & $25(6.5 \%)(4.2-9.4)$ & \multirow[t]{3}{*}{$0.197 *$} & \multirow{3}{*}{$\begin{array}{l}\text { Fisher's Exact } \\
\text { Test }\end{array}$} \\
\hline & Father & $267(95.7 \%)(92.6-97.8)$ & $12(4.3 \%)(2.2-7.4)$ & & \\
\hline & Others & $34(89.5 \%)(75.2-97.1)$ & $4(10.5 \%)(3.0-2.5)$ & & \\
\hline
\end{tabular}

Parents attitude towards childhood vaccinations among hesitant shown in Table-4

Majority of hesitant participants, $68.3 \%$ [95\% CI (52.0-82.0)], believed that it is better for their child to get fewer vaccines at the same time. Whereas, $65.9 \%$ [95\% CI (49.4-80.0)] of them were concerned that the child might have a serious side effect from a shot. About 63\% [95\% CI (47.0-78.0)] were concerned that anyone of the childhood vaccines might not be safe, while $61 \%$ [95\% CI (44.5-76.0)] of them thought that it is better for their child to develop immunity by getting sick rather than receiving a vaccine.

About $38.2 \%$ [95\% CI (22.2-56.4)] of the hesitant participants decided not to have their child vaccinated for reasons other than illness or allergy. However, one third of hesitant participants delayed their child's vaccine for reasons other than illness or allergy. Approximately 57\% [95\% CI (40.8-73.7)] believed that following the recommended vaccination schedule is a good idea for their child. Only $7.3 \%$ [95\% CI (1.520.0)] of hesitant participants believed that many of the vaccine preventable-illnesses are severe. About a quarter of hesitant participants trusted the information they receive about shots. However, $45.9 \%$ [95\% CI (29.5-63.1)] trusted their child's doctor, but only $20.5 \%$ [95\% CI (9.3-36.5)] were able to openly discuss their concerns about the shots with their child's doctor. 
Table-4: Parents attitude towards childhood vaccinations among hesitant values are in n (\%) (95\% CI), Total is 41

\begin{tabular}{|l|l|}
\hline $\begin{array}{l}\text { Delayed child's vaccine (not including seasonal flu or swine flu (H1N1) shots) for } \\
\text { reasons other than illness or allergy }\end{array}$ & $12(33.3 \%)(18.6-51.0)$ \\
\hline $\begin{array}{l}\text { Decided not to have your child vaccinated (not including seasonal flu or swine flu } \\
\text { (H1N1) shots) for reasons other than illness or allergy }\end{array}$ & $13(38.2 \%)(22.2-56.4)$ \\
\hline Following the recommended shot schedule is a good idea for your child & $22(57.9 \%)(40.8-73.7)$ \\
\hline Children get more shots than are good for them. & $21(51.2 \%)(35.1-67.1)$ \\
\hline I believe that many of the illnesses that shots prevent are severe. & $3(7.3 \%)(1.5-20.0)$ \\
\hline It is better for my child to develop immunity by getting sick than to get a shot. & $25(61.0 \%)(44.5-76.0)$ \\
\hline It is better for children to get fewer vaccines at the same time. & $28(68.3 \%)(52.0-82.0)$ \\
\hline Concerned that child might have a serious side effect from a shot & $27(65.9 \%)(49.4-80.0)$ \\
\hline Concerned that anyone of the childhood shots might not be safe & $26(63.4 \%)(47.0-78.0)$ \\
\hline Concerned that a shot might not prevent the disease & $13(33.3 \%)(19.1-50.2)$ \\
\hline Get all the recommended shots to your other infant & $10(29.4 \%)(15.1-47.5)$ \\
\hline Degree of hesitancy towards childhood shots & $22(56.4 \%)(39.6-72.2)$ \\
\hline I trust the information I receive about shots. & $9(23.1 \%)(11.1-39.3)$ \\
\hline I am able to openly discuss my concerns about shots with my child's doctor. & $8(20.5 \%)(9.3-36.5)$ \\
\hline I trust my child's doctor & $17(45.9 \%)(29.5-63.1)$ \\
\hline
\end{tabular}

The prevalence of hesitancy identified in this study was $5.8 \%$ [95\% CI (4.2-7.8)] which was below the published prevalence of other countries such as Canada (40.2\%) and France (46\%) [3, 12]. Additionally, older guardians were found to be less hesitant towards childhood vaccination. This might be explained by their previous exposures to diseases and perceived risk of disease compared to the younger generation. Putting in mind that perceived risk is influenced by emotions, source of information and previous experience, therefore people perceive high disease risk will most probably vaccinate their children, whereas people perceive high vaccine risk will less probably vaccinate them [13].

Although non-Bahraini were more hesitant it was not clear what contributed to their hesitancy. It might be related to cultural, educational, religious or philosophical beliefs $[14,15]$.

There is controversial influence of educational level on vaccine hesitancy among certain countries. In the USA, studies showed those with higher educational level were more hesitant whereas in India lower educated mothers were more hesitant [16, 17]. Our study showed no influence of educational level on vaccine hesitancy, however this should be interpreted cautiously as participants with lower educational attainment were excluded from this study.

Furthermore, in this study monthly income showed no effect on hesitancy as it might be explained by the availability, easy accessibility and governmentally funded vaccination program for Bahraini and non-Bahraini [7].

This study found that mothers were more hesitant compared to fathers in contrast to a study conducted in Tabuk area where it was found that fathers were more hesitant .7 This difference could be explained by more engagement of women in decision making in relation to their child's health. However, both studies shared the same finding in relation to beliefs about the safety and efficacy of the vaccines among guardians. Also, hesitant guardians in both studies thought that their children are over vaccinated, and they preferred them to develop immunity by getting sick rather than being vaccinated. Which could be related to misinformation about vaccines received by this group.

\section{CONCLUSION}

The prevalence of hesitancy identified in this study was $5.8 \%$ [95\% CI (4.2-7.8)] which was below the published prevalence of other countries such as Canada (40.2\%) and France (46\%) [3, 12]. Additionally, older guardians were found to be less hesitant towards childhood vaccination. This might be explained by their previous exposures to diseases and perceived risk of disease compared to the younger generation. Putting in mind that perceived risk is influenced by emotions, source of information and previous experience, therefore people perceive high disease risk will most probably vaccinate their children, whereas people perceive high vaccine risk will less probably vaccinate them [13].

\section{ACKNOWLEDGEMENTS}

The work was provided the public health in the Kingdom of Bahrain (Ministry of health) and family physician residency program.

\section{REFERENCES}

1. World Health Organization. (2014). Report of the SAGE working group on vaccine hesitancy. 12 November 2014 [Cited on 2019 July 29]. Available from: https://www.who.int/immunization/sage/meetings/ 2014/october/SAGE_working_group_revised_repo rt_vaccine_hesitancy.pdf

2. Official, D. F. (2015). Assessing the state of vaccine confidence in the United States: recommendations from the National Vaccine Advisory Committee. Public Health Reports, 130 (6): 573-595. 
3. Dubé, E., Gagnon, D., Zhou, Z., \& Deceuninck, G. (2016). Parental vaccine hesitancy in Quebec (Canada). PLoS currents, 8.

4. Karafillakis, E., Dinca, I., Apfel, F., Cecconi, S., Würz, A., Takacs, J., ... \& Larson, H. J. (2016). Vaccine hesitancy among healthcare workers in Europe: A qualitative study. Vaccine, 34(41), 5013-5020.

5. Yousif, M. A., Albarraq, A. A., Abdallah, M. A., \& Elbur, A. I. Parents' knowledge and attitudes on childhood immunization, taif, saudi arabia. J Vaccines Vaccin 2013; 5: 215.

6. Saleh, W. E., Alhawiti, S. H., Alatawi, O. A., Alamri, F. H., Albalawi, A. M., \& Merghani, T. H. (2017). Evaluation of Vaccine Hesitancy in Tabuk Population, Saudi Arabia. Int J Med Res, 3(6):2225.

7. Kingdom of Bahrain Ministry of Health. (2019). Recommended Immunization Schedule for the Expanded Program on Immunization. Cited on 2019 July $17 . \quad$ Available from: https://www.moh.gov.bh/HealthInfo/Immunization $\mathrm{s}$ ?lang=en

8. World Health Organization. (2015). National immunization coverage scorecards estimates for 2015. Cited on 2019 July 29. Available from: https://www.who.int/immunization/global_vaccine _action_plan/WHA_Scorecards_2015.pdf?ua=1

9. Pourhoseingholi, M. A., Vahedi, M., \& Rahimzadeh, M. (2013). Sample size calculation in medical studies. Gastroenterology and Hepatology from bed to bench, 6(1), 14-17.

10. Countrymeters. Bahrain population. Cited on 2017 May 22. Available from: https://countrymeters.info/en/Bahrain

11. Opel, D. J., Mangione-Smith, R., Taylor, J. A., Korfiatis, C., Wiese, C., Catz, S., \& Martin, D. P. (2011). Development of a survey to identify vaccine-hesitant parents: the parent attitudes about childhood vaccines survey. Human vaccines, 7(4), 419-425.

12. Rey, D., Fressard, L., Cortaredona, S., Bocquier, A., Gautier, A., Peretti-Watel, P., \& Verger, P. (2018). Vaccine hesitancy in the French population in 2016, and its association with vaccine uptake and perceived vaccine risk-benefit balance. Eurosurveillance, 23(17).

13. World Health Organization. (2019). Vaccination and trust. Cited on 2019 July 30. Available from: http://www.euro.who.int/en/health-topics/diseaseprevention/vaccines-andimmunization/publications/2017/vaccination-andtrust-2017

14. Nasim, O., Khan, S., Fahad, M. S., \& Ahmad, K. (2015). The perception of polio: factors enabling \& impending its eradication in multiple districts of Khyber Pakhtunkhwa province, Pakistan. Journal of Medical Students, 1(2):41-46.

15. Machekanyanga, Z., Ndiaye, S., Gerede, R., Chindedza, K., Chigodo, C., Shibeshi, M. E., ... \& Kaiser, R. (2017). Qualitative assessment of vaccination hesitancy among members of the apostolic church of Zimbabwe: A case study. Journal of religion and health, 56(5), 1683 1691.

16. Bocquier, A., Ward, J., Raude, J., Peretti-Watel, P., \& Verger, P. (2017). Socioeconomic differences in childhood vaccination in developed countries: a systematic review of quantitative studies. Expert review of vaccines, 16(11), 11071118.

17. Dasgupta, P., Bhattacherjee, S., Mukherjee, A., \& Dasgupta, S. (2018). Vaccine hesitancy for childhood vaccinations in slum areas of Siliguri, India. Indian journal of public health, 62(4), 253. 